\title{
Article
}

\section{Evaluation Of Aviation-Based Safety Team Training In A Hospital in the Netherlands}

Author Details (please list these in the order they should appear in the published article)

Author 1 Name: Dirk F. de Korne, PhD MSc

Department: Rotterdam Ophthalmic Institute / institute Health Policy and Management / Singapore National Eye Centre University/Institution: Rotterdam Eye Hospital / Erasmus University Rotterdam / Duke-NUS Graduate Medical School Singapore Town/City: Rotterdam

State (US only):

Country: Netherlands

Author 2 Name: Jeroen D.H. van Wijngaarden, PhD MA

Department: institute Health Policy and Management

University/Institution: Erasmus University Rotterdam

Town/City: Rotterdam

State (US only):

Country: Netherlands

Author 3 Name: Cathy van Dyck, PhD

Department: Department of Organization Sciences

University/Institution: VU University

Town/City: Amsterdam

State (US only):

Country: Netherlands

Author 4 Name: U. Francis Hiddema, MD

Department: Board

University/Institution: Rotterdam Eye Hospital

Town/City: Rotterdam

State (US only):

Country: Netherlands

Author 5 Name: Niek S. Klazinga, MD PhD

Department: Department of Social Medicine

University/Institution: University of Amsterdam

Town/City: Amsterdam

State (US only):

Country: Netherlands

NOTE: affiliations should appear as the following: Department (if applicable); Institution; City; State (US only); Country.

No further information or detail should be included

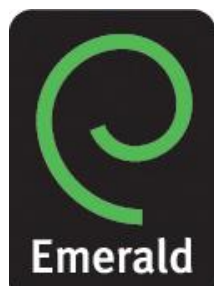


Corresponding author: Dirk F. de Korne, PhD MSc

Corresponding Author's Email: dirk.de.korne@snec.com.sg

\section{Acknowledgments (if applicable):}

Biographical Details (if applicable):

\section{[Author 1 bio]}

Dirk F. de Korne, PhD MSc was Senior Consultant Quality and Safety at the Rotterdam Eye Hospital and Post-Doctoral Research Fellow at the Rotterdam Ophthalmic Institute. Currently he serves at the Deputy Director of Health Innovation at the Singapore National Eye Centre and has appointments as Assistant Professor at the institute of Health Policy and Management at Erasmus University Rotterdam, Netherlands, and Health Services \& Systems Research, Duke-NUS Graduate Medical School Singapore.

[Author 2 bio]

Jeroen D.H. van Wijngaarden, PhD is Assistant Professor at Health Services Management and Organization, institute of Health Policy and Management at Erasmus University Rotterdam, Netherlands.

\section{[Author 3 bio]}

Cathy van Dyck, PhD is Assistant Professor at the Department of Organization Sciences, VU University Amsterdam, Netherlands.

[Author 4 bio]

U. Francis Hiddema, MD is Chief Executive Officer of the Rotterdam Eye Hospital, Netherlands.

[Author 5 bio]

Niek S. Klazinga, MD PhD is Professor at the Department of Social Medicine, University of Amsterdam, Netherlands.

\section{ABSTRACT}

Purpose To evaluate the implementation of a broad-scale team resource management (TRM) program on safety culture in a Dutch eye hospital, detailing the program's content and procedures. Aviation-based TRM training is recognized as a useful approach to increase patient safety, but little is known about how it affects safety culture.

Design/methodology/approach Pre- and post-assessments of the hospitals' safety culture was based on interviews with ophthalmologists, anaesthesiologists, residents, nurses, and support staff. Interim observations were made at training sessions and in daily hospital practice.

Findings The program consisted of safety audits of processes and (team) activities, interactive classroom training sessions by aviation experts, a flight simulator session, and video recording of team activities with subsequent feedback. Medical professionals considered aviation experts inspiring role models and respected their non-hierarchical external perspective and focus on medical-technical issues. The post-assessment showed that ophthalmologists and other hospital staff had become increasingly aware of safety issues. The multidisciplinary approach promoted social (team) orientation that replaced the former functionally-oriented culture. The number of reported near-incidents greatly increased; the number of wrong-side surgeries stabilized to a minimum after an initial substantial reduction.

Research limitations/implications The study was observational and the hospital's variety of efforts to improve safety culture prevented us from establishing a causal relation between improvement and any one specific intervention.

Originality/value Aviation-based TRM training can be a useful to stimulate safety culture in hospitals. Safety and quality improvements are not single treatment Interventions but complex socio-technical interventions. A multidisciplinary system approach and focus on 'team' instead of 'profession' seems both necessary and difficult in hospital care. 


\section{Background}

Studies have shown that too often health care is hazardous rather than beneficial, with unnecessary morbidity and mortality (Kohn et al., 1999; Haynes et al., 2009; Leape et al., 2009; Classen et al., 2010). Human factors seem to cause most incidents and failures (Reason 1990; Griffin and Neal, 2000; van Dyck, 2000). A study in Dutch hospitals revealed that 56\% of unintentional harmful events were related to health professionals' knowledge, behaviour, or skills (De Bruijne et al., 2007). In contrast, technical and organizational factors played a minor role at $4 \%$ and $14 \%$ respectively. The researchers attribute the other $26 \%$ to a combination of 'others factors', 'patient factors' and 'not able to evaluate'. Health care managers therefore are urged to focus on patient safety and quality while they are simultaneously asked to reduce costs and increase efficiency. Such circumstances are not exclusive to health care management. Comparable challenges are found in other industries, some of which have found effective approaches to focus on quality in combination with increasing efficiency and client centredness. Many authors have advocated the use of innovations from other industries in health care (Berwick 1989; Hudson 2003; Singh et al. 2006; Nance 2008). It is widely believed the application of industrial quality and safety methods can result in significant improvement in clinical processes and medical care outcomes.

Safety as dimension of quality

Although safety is often dimensioned as being part of the broader 'quality' concept (with effectiveness, efficiency, accessibility, acceptability, equitability), the last decennium has seen increasing awareness and focus on (patient) safety and some talk about a 'new health care discipline'. The Institute of Medicine defined patient safety as 'the freedom from accidental injury; ensuring patient safety involves the establishment of operational systems and processes that minimize the likelihood of errors and maximise the likelihood of interceding them when they occur' (IOM, 1999). And also from ancient history on, the medical world states with Hippocrates: Primum non nocere - 'First, do no harm'. In the last decade, different studies have shown that health care delivery is too often hazardous. In Dutch hospitals, about 1,960 patient die annually and 33,000 (2.9\% of all inpatients) are harmed due to preventable, unnecessary action (Langelaan et al. 2010). The costs of these events are estimated at $€ 161$ million, 1 percent of the national hospital care budget (Hoonhout et al. 2009).

\section{Hospitals as complex services organizations}

Health care comprises a series of activities between a care seeker, the patient, and a care deliverer, in which the care deliverer relates his or her performance partly to scientific knowledge to achieve a goal -health, well-being- that will be judged against the patient's own subjective values (Klazinga 1996). Health care can thus be seen as medical practice when applying knowledge, and a service delivery when providing a service, which results in specific responsibilities for the medical profession and the hospital organization towards quality and safety.

Like other service industries, hospital care is characterized by an intangible product whose production by the medical specialist and consumption by the patient are inseparable. In the interaction of doctor-patient the patient's question (in the context of a health problem and seen as a health care demand) and the doctor's answer (in the context of medicine and seen as a response to a health need) constitute the essence of the production process. The level of autonomy of the provider to make decisions is very high: a medical specialist delivers an individualized service in a context of limited possibilities. Quality and safety improvement in health care also relates to the organization of the care. All doctor-patient contacts take place within a broader production process of service delivery. The production process of specialist care is part of a composite of production process that together results in the primary process of patient care within the organisational context of a hospital. Where the physician of yore practiced at home, the increasing number of specialists and use of technology since the beginning of the $20^{\text {th }}$ century compelled them to work (partly) in hospitals. Hospitals, a century before created as 'houses of God' and 'houses for the poor', increasingly became institutions where 'scientific treatments' could be obtained that could not be provided at home (Van Lieburg \& Richter, 1993). Thus, the modern 
hospital as a complex service organization providing specialized medical care took shape. Currently, a development to 'focussed factories' for specific patient groups (e.g. orthopedics, oncology, ophthalmology) is visible, giving rise to discussions about a desirable concentration and distribution of general and specialized care (see for example Christensen et al., 2009). These context changes need to be taken into account when approaching quality and safety issues in today's hospital care.

\section{Health care compared to other industries}

Notwithstanding the characteristics of health and hospital care, other industries also face negative factors related to organizational and professional issues. Some have found approaches to mitigate their effects on quality and safety. Comparing health care safety patient safety outcomes, for example - to other industries is difficult because adverse-event reporting - even within the same sector - uses different definitions and weighting. For example, civil aviation uses 1 million departures as the relevant volume parameter; military aviation uses the number of flight hours. In many industries, the weighting process reflects how comfortable the organization or industry is with its risk exposure. For example, there were 661 fatal accidents on Dutch roads in 2011, a number that was communicated to the public (Min I\&M, 2012). Fatalities are often weighted by travel convenience and the total number of miles travelled.

Amalberti et al. (2005) have performed risk assessments and compared different industries. They used the rate of catastrophic events per exposure among industries with those in health care. Some sectors continue to have low safety levels (e.g. transport by a micro light aircraft or helicopter); some are stagnant at average safety levels (e.g. road safety); some are at safe levels (e.g. petrochemical industry), and the best have achieved safety levels beyond $10^{-6}$. Viewed through this lens, accident rates in health care currently range from $10^{-1}$ to $10^{-4}$.events per exposure. Due to the number of iatrogenic adverse events hospitals thus can be characterized as 'unsafe'. Different studies found that $14-33 \%$ of patients in U.S. hospitals were harmed by medical care, with 44-63\% of those cases being judged as being preventable (Landrigan, et al. 2010; Levinson, 2010; Classen et al., 2011). Assessing the issues retrospectively, many current quality (safety) issues in health care are related to organizational characteristics, process complexity, and hospital culture (Leape et al. 2009; Hudson 2003; Sexton et al. 2000; Flin et al. 2008). These issues are, however, comparable to (earlier) situations in other industries.

\section{Aviation-based safety team training}

To improve human factors issues (e.g. pilot awareness or fatigue), related to safety in aviation, Crew Resource Management (CRM) is used to train cockpit crews. CRM can be described as training on non-technical skills of crews which is focussed on increasing awareness of safety, its causes and characteristics, improvement of communication, leadership and reflection on one's own behaviour (Pizzi et al., 2001; Powell, 2006). Cockpits crews worldwide are mandatorily trained in CRM. Aviation safety outcomes in the US show that between 1994 and 2006, the average rate of fatal accidents decreased from 0.05 to 0.022 per 100,000 departures, which led Pronovost et al. (2009) to conclude that 'health care's slow disappointing efforts to improve safety contrasts with the remarkable success of aviation safety.'

CRM training has been suggested to improve human-factor-related healthcare safety (Pizzi et al., 2001; Bleakley et al., 2004; Musson \& Helmreich, 2004; Powell, 2006; Yule et al., 2006; Dunn et al., 2007; Gore et al., 2010; Neily et al., 2010; Oriol, 2006; Rabøl et al., 2010). CRM is used in aviation for non-technical skills training and focuses on increasing awareness of safety, its causes and characteristics, improvement of (team) communication, leadership, and reflecting on individual behaviour (Edmondson, 2003; Grogan et al., 2004; Flin et al., 2006; Haig et al., 2006; Sexton et al., 2006; Rabøl et al., 2010). In health care, professional staff (for example, physicians and nurses) are exposed to the same training concepts (referred to as Team Resource Management (TRM) which term we will use from now on) to improve safety culture (Grogan et al., 2004; Rabøl et al., 2010). According to McConaughey (2008), the training provides team members with the tools, knowledge, skills and attitudes that they need to respond to demanding and difficult situations while minimizing the risks of errors. TRM can include different educational approaches, such as 
lectures, videos, simulators and on-the-job behaviour feedback. While there are different handbooks, one standardized methodology or prescription for 'the TRM intervention' does not exist (Bleakley et al. 2004; Fraher, 2005a; ibid. 2005b). Recent studies use different names ('crew resource management', 'team resource management', 'medical team training', 'human factors training' (Edmondson 2003; Neily et al. 2010; Rabøl et al. 2010) and vary widely on content and implementation.

Although there is no high quality evidence of the effectiveness of TRM, different studies have shown positive results (Buljac et al., 2010). For example Neily et al. (2010) found that participation in a Medical Team Training at Veterans Health Administration was associated with lower surgical mortality upon evaluation one year post-implementation. A retrospective study with a contemporaneous control group was conducted. Outcome data were obtained from a surgical quality improvement program and from structured interviews. The analysis included 182,409 sampled procedures from 108 hospitals. The training program included 2 months of preparation, a 1-day conference, and 1 year of quarterly coaching interviews and required briefings and debriefings in the operating room and included checklists. The 74 facilities in the training program experienced an $18 \%$ reduction in annual mortality (RR $0.82 \mathrm{Cl} 0.76-0.91, \mathrm{p}=.01$ ) compared with a $7 \%$ decrease among the 34 facilities that had not yet undergone training (RR $0.93 \mathrm{Cl}$ 0.80-1.06, p=.59). McCulloch et al. (2009) described the effect of aviation-based training on technical performance and outcome in the operating room (OR). They performed an uncontrolled before-after study of the effect of non-technical skills training on attitudes, teamwork, technical performance and clinical outcome in laparoscopic cholecystectomy (LC) and carotid endarterectomy (CEA) operations in one UK teaching hospital. A 9 hours classroom non-technical skills course was offered to all staff, followed by 3 months of twice-weekly coaching from CRM-experts. Non-technical skills $(p=0.021)$ and attitudes ( $p=0.007)$ improved after the training and operative technical errors $(p=0.009)$ and non-operative procedure errors $(p<0.001)$ declined. They concluded that the hypothesis that the OR team could substantially reduce errors and adverse surgical outcomes has become widely accepted, but evidence supporting it is scant. Both in aviation and health care, little is known about how TRM affects the 'black box' of safety culture. A systematic review conducted by Rabøl et al. (2010) showed that more than half the studies ended evaluation within six months, but Sax et al. (2009) concluded TRM's influence on personal behaviour and empowerment may take years to be integrated into the culture.

Although definitions vary, safety culture is commonly defined as "the product of the individual and group values, attitudes, perceptions, competencies and patterns of behaviour that determine the commitment to, and the style and proficiency of an organization's health and safety management" (Nieva and Sorra, 2003, pp.ii18). Based on selected literature, the following dimensions appear to determine a safety culture and are TRM program focus points (Bogner, 1994; van Dyck, 2000; Nieva and Sorra, 2003; Hoffman et al., 2006; Nance, 2008; Singer et al., 2010):

1. Awareness of risks (anticipation of approaching conditions, acceptance of human factors in safety);

2. Aversion to report errors (too rigid a focus on prevention, transparency with respect to errors, not covering up near misses);

3. Social orientation (curtailing operator autonomy while preserving operator authority, increasing knowledge and skills in communication and helping);

4. Mastery of risks (reporting errors, correction and analysis of errors, learning from (near) incidents).

Since it is difficult to measure culture and not much is known on how TRM is applied in practice, a thorough analysis of the characteristics of TRM and how it is implemented in practice is needed to assess if and how it affects safety culture. We therefore studied the development, implementation, and subsequent experiences of a hospital-wide TRM program in an eye hospital in the Netherlands. Staff members (medical, management, support) from all hospital departments involved in patient care participated. Our research question was: "How is an aviation-based TRM program applied in an eye hospital and how does it affect the hospital's safety culture?"

\section{Methods}

A mixture of methods was used (Bowling, 2002; Creswell, 2003; Yin, 2003). First, we have described the development and content of the TRM-program in detail. The case hospital is the only eye hospital in the Netherlands (thus serving 16 million people), 
providing secondary eye care for the region and tertiary care for the country. As a major referral centre, it handles approxim ately 140,000 outpatient visits and 14,000 surgical cases per year. Some 30 specialized ophthalmologists, 4 anaesthesiologists, and 4 internists maintain their practices through a partnership with the hospital. The hospital, which has a total of 400 employees, operates resident and fellow programs and a research institute. All $n=274$ hospital staff involved in patient care were exposed to the TRM program. The training was mandatory for all staff but physicians. The numbers of staff types and respective participation rates are described in Table 1.

$>$ insert Table 1 about here

We did observations during 8 multidisciplinary group meetings (medical and nursing staff, administrative staff, and aviation experts) where the program was developed. Discussions on content and process of the training were transcribed. We studied related documents (exercise material and assignments used during the sessions, minutes of the group meetings, hospital policy reports and announcements and safety related hospital protocols). Second, we performed assessments of the hospitals' safety culture. Before the TRM-program was introduced (T0, January 2007), 19 semi-structured face-to-face interviews with ophthalmologists (5), anaesthesiologist (1), residents (3), nurses (5), administrative staff (3) and management (2) were held. The respondents were selected randomly, taking into account a representation from different functions and departments. The interviews were built around recent critical incidents using the critical incident technique (Flaganan, 1954) and the experiences of respondents and guided by a topic list based on the safety culture dimensions presented in the Background paragraph. Sample questions are 'Could you tell something about lesson from a recent incident?', 'What did you do after the incident happened?', 'How often do you report errors?', and 'How do you experience your manager when you report an (near) incident?'. We have described details on the methodology of the interviews earlier in Van Dyck et al. (2013). After the TRM-program (T1, December 2009), 11 interviews were conducted with ophthalmologists (3), residents (2), nurses (3) administrative staff (2) and a manager who also were interviewed at T0, using the same questions to observe differences after the introduction of the program.

Third, we conducted unstructured observations during the program. At 24 TRM sessions, the reactions, behaviours and discussions were written down by a participating researcher. Additionally, unstructured observations were conducted during daily operational practice in the hospital since one of the participating researchers was also involved in the hospital as quality and safety consultant. In this action research approach, the researcher is an active project participant and supports the organization by analysing and implementing new methods. The researcher simultaneously and scientifically measures project results to extract general and generalizable knowledge (Eden \& Huxham, 1996). To reduce the risk of bias, one other researcher (CD) was carrying out the majority of the interviews while two other researchers (JW and NK) provided independent peer review during the analysis. Additionally, a thorough member check was performed during different phases of the data collection and data analysis. During the program, 2 ophthalmologists, 2 nurses and 1 manager were interviewed about their experiences with the program. All interviews were a maximum of 1.5 hours and were transcribed verbatim. We structured and analyzed the content from the documents and the interviews according to tags drawn from the safety dimensions (see the list of tags mentioned above as related to the four safety culture dimensions, e.g. anticipation of approaching conditions, too rigid focus on prevention, etc.).

\section{Results}

\section{Application of TRM}

Team Resource Management (TRM) was introduced in 2007 in the case hospital as part of a long term strategy of diffusing innovations from aviation (see de Korne et al., 2010). The reasons for launching TRM were repeated incidents with wrong-side eye surgeries (average of six per year in about 11,000 surgeries). The introduction of a time-out checklist before surgery in 2004 led to a serious improvement to zero or one incident a year, but its goal - zero wrong-side surgeries - was not met. Analysis of the incidents showed that the time-out checklist was not performed for all surgeries and that nurses had not always dared to speak up. 
Aviation safety experts with experience in CRM training with flight crews were asked by the hospital board to develop a comparable TRM program for hospital staff. In close cooperation with a multidisciplinary group (medical and nursing staff, administrative staff, and aviation experts) a TRM program was developed. In accordance with aviation's central CRM principles, the hospital wanted to increase communication and management skills by effective use of people and resources. The program had four elements: (1) safety audits of processes and (team) activities and feedback by aviation experts, (2) classroom training sessions and lectures on safety awareness and human factors by aviation experts, (3) a flight simulator session in Boeing 737-800 aircraft simulator with feedback on team performances, and (4) video recording of (team) activities and feedback by aviation experts ('black box'). A cyclical approach is used by applying lessons and results of one element successively in the others (e.g., the videorecordings are used during the classroom sessions).

The first sessions started in 2007 with a pilot project at the ambulatory surgical centre and were mandatory for everyone but physicians. The TRM training was then provided on an on-going basis and extended to outpatient clinic teams. Participation in the training was embedded in the license agreement between ophthalmologists and the hospital. During the entire program, the aviation experts played an important role in design and co-creation. The aviation safety experts were viewed as credible by the participants, given the comparability between aviation/health care and cockpit/OR, and the fact that they did not occupy a position in medical hierarchy: "You take him seriously because he's an expert from aviation, and therefore able to approach all the participants in the training - doctors and nurses - as if they were on the same level" (nurse 3). It helped to confront medical staff with comparable safety challenges and solutions in aviation because it is an industry they regard as interesting: "Both the cockpit and the OR are worlds of glamour" (manager 2).

1. Safety audit. After an initial lecture on safety for the medical and administrative boards, aviation experts performed a safety audit of surgical care processes. During process walk-throughs, safety issues were recognized in prospective risk analysis and information about (recent) near incidents was gathered (retrospective analysis). The aviation experts used the 'SHEL model of human factors' to examine and elucidate the safety issues (Molloy \& O'Boyle, 2005). The SHEL model is named after the initial letters of its components' names Software (procedures, protocol, training), Hardware (machines, medical instruments), Environment (operating theatre, wards, consultation room, and Liveware (human factors: doctor, nurse, other health care professional or patient). This model was in particular useful where it argues that mismatches at the interface between its components (e.g. liveware hardware) are often conducive to medical errors. Identified risks (see Table 2 for examples) were discussed with the multidisciplinary staff.

>> insert Table 2 about here

The results of the audits were incorporated in the materials for the classroom sessions and frequently showed the relevance of focusing on the whole patient process. Root causes of wrong-side surgery, for example, were often detected in parts of the logistical and administrative pre-operative processes.

2. Classroom based training. The safety audit was followed by three four-hour interactive classroom sessions provided by aviation experts (Table 3).

>> insert Table 3 about here

Session 1 consisted of a presentation and discussion of the context of patient safety (human factors) and the consequences and necessary tools of teamwork (communication). Session 2 elaborated on (i) the theory and practice of situational awareness (being aware of surrounding actions to understand how information, events, and one's own actions impact goals and objectives) and (ii) 
decision making (with discussion of causes and appropriate reactions to faults and (un)acceptable risks). Session 3 addressed personality and (un)safe behaviour, leadership and accountability. All sessions made use of recent hospital cases (Figure 1).

>> insert Figure 1 about here

The classroom sessions were small-scale and highly interactive. Participants showed openness to each other related to their individual safety behaviour. For example, during an outpatient team session, an ophthalmologist - initially highly resistant to the program - showed increasing recognition of the relevance of open communication. During the first session, he refused to participate: "I'll get involved in all this safety stuff only when organizational problems with capacity are solved." In the next session, he sat just behind the inner circle but was involved in the discussion. In session three, he took a seat near the team and participa ted highly. During the session a nurse said that she sometimes felt intimidated when he yelled or cursed. He reacted: "Ladies, when I shout or curse, I'm basically angry with myself, not you." We observed a literal sigh of relief in the training room. The nurse replied, "Dr._., I'm so happy to hear you say this." Later in an interview, the nurse indicated that this one event would have made the training worthwhile. The story is still being recounted among nurses in the hospital.

3. Flight simulator session. A closing session took place in a Boeing 737-800 flight simulator, an new environment in which all staff was outside the regular hospital context and, moreover, the trainees could not fall back on their professional technical skills. The vast majority had never been in such environment and therefore the historical and classic medical hierarchy based on skills and experiences did not exist. Newly developed TRM skills were applied in an external, exciting environment that diminished common roles and hierarchy. The flight simulator was also used to 'seduce' physicians into the TRM program as it was obligatory to attend the classroom sessions before participation in the simulation session.

4. Video feedback. Inspired by aviation, a 'black box' approach was introduced in 2008. The aviation safety experts videotaped ophthalmic surgeries monthly to give the team feedback on the application of the safety procedures taught during the classroom sessions. Adherence to protocols for the production, use, and distribution of the images was documented. The aviation black box is automated, but for financial constraints and juridical reasons the hospital used a handheld video recorder.

Videotaping team activities were not easily accepted and fully-automated use has not yet been applied. Medical staff was initially hesitant, fearing that recorded unexpected outcomes could be used against them. Only ophthalmologists who participated in the TRM program and trusted the aviation safety experts consented to having their surgeries videotaped, but with the stipulation that the images be taken with a handycam and used solely for their own training. The chief ophthalmologist, who had declared his willingness in an earlier stage of the program, consented to make the recordings available to all the hospital's attendings, residents, and nurses, stimulating others to get involved in the program. In the end, $75 \%$ of the ophthalmologists participated in the training. Top management was involved in developing and championing the TRM program throughout.

\section{Assessing the hospital's safety culture}

1. Awareness of risks. From interviews and observations, it was clear that anticipation of approaching safety threats was a recurrent session topic. Participants talked about a lack of standards and interoperability and appealed for correction: "There are no strict protocols for what I do and what the surgeon does. Continuous evaluation and risk assessment depend on the surgeon" (resident 2). As a result of the discussions, multidisciplinary, standard operating procedures were agreed upon, including a preoperative briefing (with task division) and time-out. Situational awareness and the influence of individual human factors was a recurrent topic in the video feedback items (Table 4).

>> insert Table 4 about here 
The videotapes revealed team-specific differences in performing the time-out procedure and using the safety communication rules agreed on during the TRM training. They also showed that the absence of team members at the pre-operative briefing resulted in less structure and more communication gaps during surgery. As one aviation safety expert said, "It is a new and inspiring experience for ophthalmologists to see their own performance ... within their environment. It confirms the notion that surgery is a team activity." It was difficult to deny teamwork failures when they were clearly revealed on tape. One video showed how a lack of briefing resulted in uncertain behaviour of a resident and an unexpected pain movement of a locally-anesthetized patient. During a feedback session with staff, most ophthalmologists blamed the resident. The TRM trainer, however, confronted the ophthalmologist (captain) rather than the resident (co-pilot) with the situation and focused on a responsible leadership role.

2. Aversion to error-reporting. Teams were convinced that eye surgery is highly unpredictable and most complications are not preventable. The trainer responded: "You're talking about complications like we did in aviation 30 years ago. Bad weather, for instance, was called a complication. Today we say, no, weather conditions can be anticipated, so don't call it a complication". This seemed to create awareness and resulted in discussions about the differences between complications, medical errors, and adverse events. The number of reported near misses increased by about 300\% (78 to 409) in the three years following the introduction of the TRM program. Some surgeons, however, indicated that reporting errors was still difficult. "You know that you're not guilty or being blamed, but it still feels like it" (ophthalmologist 4).

Only $18 \%$ of the (near) incident reports over the past three years were submitted by ophthalmologists. Considering the one-to-one supervision model in which medical residents are trained, leading by example turned out to be a crucial factor influencing error reporting. "Basically you're looking at the work practices of your supervisor and trying to copy that" (resident 1). Others indicated that they were highly dependent on the existing leadership culture. "You have to take the culture for granted; you know it's part of the game when you want to become a specialist" (resident 3). During sessions, senior ophthalmologists claimed there were no barriers for residents to talk about errors. Residents did not agree: "I cannot comfortably report errors and concerns to my supervisor" (resident 1). As a result of the training, seniors and juniors openly discussed barriers.

3. Social orientation. During the program, the risks of the monodisciplinary focus (both between ophthalmologists and anaesthesiologists and between physicians and other groups) and their own rules and behaviour were clearly demonstrated. An ophthalmologist spoke about the different worlds of surgery and anaesthesia: "I don't see myself telling anaesthetists that they have to react to beeps of their equipment. That's their responsibility" (ophthalmologist 4). The aviation expert, however, explained that each team member influenced patient outcomes. Respondents indicated that the training revealed basic communication (mis)understandings between professionals: "During medical training you only learn how to be a technically good ophthalmologist. You learn from your supervisor. I have never learned anything about team communication, other than from experience" (ophthalmologist 3).

Before 2007, only monodisciplinary training was provided. The absence of multidisciplinary team meetings was seen by nurses as a deficiency since misunderstandings between the professions were common. The current TRM training partly filled the gap in creating a meeting and discussing platform. As one nurse said: "To be together with the multidisciplinary team is one of the greatest parts of this training. Usually, doctors and nurses are separately trained and talk about each other. Now we're talking with each other" (nurse 2). Discussion of effective communication and the roles of personality and behaviour manifested especially in the later classroom sessions. Respondents indicated that the program had increased their awareness about their individual roles and its effects on the team. "Having final responsibility for the treatment of the patient, I am very happy with TRM training. Being together with all staff is good for reflection on the surgical process and the social relations between different people. And of course it's also nice to operate once on a real flight simulator" (ophthalmologist 4). The flight simulator was used to increase awareness and social orientation as well as an incentive for physicians to become involved. 
4. Mastery of risks. In the interviews, especially nurses indicated that they focused more on trying to learn from incidents because of TRM. To improve safety they now looked at the whole system for relevant changes instead of only the direct (near) incident causes, as shown in this example: "For a long time we tried to prevent having unexpected empty gas cylinders during surgery by not shifting nurses when a cylinder was almost empty, but it still happened frequently. As a result of the TRM, we have built a system with an alarm on the gas cylinder that goes off when the cylinder is almost empty" (nurse 3). Starting in 2008, near misses and incidents were analysed on a department, instead of central level. (Near) incident reporting committees were installed for (1) surgical issues, (2) outpatients and (3) facilities and administration. The committees consist of an ophthalmologist (1 and 2) or facility manager (3) as chair, a nurse manager, and a safety consultant. All (near) incident reports are analysed and categorized on (estimated) frequency and severity. As a result, feedback and suggestions for action are provided to the reporters, involved professionals and departments, and (higher) management.

Observations combined with interview data showed that employees are more critical about risks in their work, and have become aware that the ability to reduce or eliminate the likelihood of adverse events should be a shared, interdisciplinary responsibility. When the trainer asked during an early session whether the hospital was a safe place to work, many participants raised their hands. When asked the same question at the end of the session, the number of raised hands was substantially lower. Supportive actions for safety and (near) incident management were observed at all organizational levels. As part of the TRM program, various safety supporting actions were taken in the hospital (Table 5).

>> insert Table 5 about here

Safety officers, for example, became involved in incident analysis and top management began safety rounds. On the department level, every meeting started with safety topics, incidents, and near misses. Multidisciplinary standard operating procedures and safety instructions for patients were developed. Safety aspects were also added to existing internal quality audits. These observations indicate that the TRM program has resulted in an increasing application of (hospital-wide) safety-supporting practices.

\section{Discussion}

The TRM program was co-developed and implemented by healthcare professionals and aviation specialists. Aviation proved to be an inspiring example for medical professionals. The involvement of aviation specialists stimulated a broader perspective on safety issues without focusing too much on medical-technical details. Furthermore, the programs introduced the hospital's first multidisciplinary platform and training. Observations showed that this helped participants to identify and change safety-related patterns of behaviour between professions, such as doctor-nurse and ophthalmologist-resident. The observations and interviews suggest that safety awareness has increased as a result of the training. Whether ophthalmologist's compliance with the time-out procedure has increased is not yet evident, but a substantial decrease of wrong-site sentinel events due to using time-outs has been established (de Korne et al., 2010). Over the period 2010 to 2012, one incident per year was reported while number of reported near-misses increased to nine. Due to the duration as well as the design of this case study, we are not able to make distinct statements on a longer-term and sustainable culture change.

We recognize several limitations. The study was observational, and the hospital's variety of efforts to improve safety culture prevented us from establishing a causal relationship between improvement and any one specific intervention. We tried to incorporate more quantitative outcomes from an internal hospital report. The hospital performed safety culture surveys (van Dyck, 2000 ) in 2007 and an internal hospital report in 2009 (REH 2010). Due to response rates (53\% and 38\% respectively) and having only 22 paired respondents, no significant changes could be found. A second limitation is that a study in an eye hospital may not be generalizable to other hospitals. Other studies in different settings, however, have shown similar results (Rabøl et al., 2010; Catchpole et al., 2010). Third, we did not link changes in culture to patient outcomes other than wrong-side surgery. Relating the 
visual acuity outcomes of cataract surgery to the hospital's safety culture would have been useful and interesting, had data been available and reliable.

Many authors have advocated the application of innovations from other industries in health care. Doing so, however, is not easy. One of the myths of medicine is that it readily adopts innovation. Balas et al. (1995) showed that, absent significant short term financial remuneration for practitioners or hospitals, implementing clinical studies in standard medical practices takes 17 years. Adopting new safety procedures could take even longer. According to Denham (2005) the strongest catalysts for change are new codes of remuneration for caregivers in computerized systems, which currently, and also in this study, are not closely related to patient safety. Incentives for innovation in the case hospital were related to its recent history. Back in the early 1990's, the hospital in this study was at risk of being taken over by an academic hospital. The Dutch government would allow it to remain a stand-alone hospital if it achieved high production volumes, low costs, and a patient centered approach. Hospital management decided to try to learn from other industries by adopting several of their quality and safety methods. Implementation took place over a period of almost 20 years, during which the same CEO and CFO presided. The CEO (an MD) played an important role in championing the program and 'selling' it to the medical staff.

Healthcare organizations, like accountancy and law, are professional and characterized by high levels of individual autonomy (Freidson 2001; Mintzberg 1983; Fulop, 2012). The nature of medical work, with its complexity and specific knowledge requirements can only partly be standardized. Because of medical autonomy, protocols in health care also carry a different weight compared to many other industries (e.g. Bogner, 1994). Medical professionals are often not held accountable and do not feel obliged to uphold protocols. Hospitals therefore lack the aviation industry's strict system of registration and accountability for cases in which checks are not performed.

The fact that hospitals are professional organizations seems to have implications for how they diffuse innovations. Our study showed that the diffusion of an innovation in eye hospitals takes more time and requires a longer-term perspective than other industries, and revealed many different influencing factors. Greenhalgh et al. (2005) have conceptualized a model for the spread and sustainability of innovations in service delivery and health organizations. In accordance with the earlier theory of Rogers (1995), they showed that diffusion is dependent on the characteristics of the innovation itself (and its resource system) as well as the 'user system' (with system antecedents and readiness for innovation, the adopter, assimilation, the implementation process) and its links to the outer context (socio-political climate, incentives and mandates, interorganizational norm-setting and networks).

The 'user system' is one of the most striking differences between industrial settings and hospital care. The most important resources (physicians) are not a formal part of the organization that acts as a threshold for the diffusion of changes. In our case study, physicians cooperate in partnership with the hospital, giving it few opportunities to require physician involvement in quality and safety initiatives. How organizational learning takes place in health care is very much influenced by the position of the physician and the relation between caregivers and others. Based on a study on the application of an aviation-based TRM training in neurosurgery and cardiac surgery, France et al. (2008) however indicate that health care TRM requires physician leadership that is supported by a broader organizational safety culture. As shown in our study, teamwork is important for quality and safety improvements in health care; learning should be a collective process. Strong medical competences in combination with nontechnical skills and teamwork are highly important for effective work, productive relations, and realizing organizational improvements in high-reliability bodies such as hospitals (Argyris 1991; Baker et al. 2006; Van Stralen, 2008). Highly educated professionals are usually excellent in individual and single loop learning: they have had to learn to define and solve problems by themselves. Since they are good at their jobs, however, they rarely experience failure and usually react defensively or blame others when something goes wrong (Argyris 1991). Our observation where an ophthalmologist during the TRM classroom sessions confesses that he is basically angry with himself when shouting at the team resembles strongly with observations in an earlier study on the application of a comparable TRM approach in a pediatric intensive care unit: 'if an attending physician yells or shows any other anger behavior, it reflects the physician's fear and not the performance of the team' (Van Stralen 2008, pp.83). Acknowledging and identifying failures is necessary for 'double-loop learning', which occurs when error is detected and corrected in ways that involve modifying the organization's underlying norms, policies, and objectives (Argyris 2004). As observed in the case study, there is a difference 
between individual and collective learning in teams. Our positive findings on the use of video feedback are in line with earlier studies that showed that its use stimulates discussion and augments learning of team behaviors (e.g. McConaughey, 2008).

Health care professionals seem to have a different view on teamwork than peers in other industries. Sexton et al. (2000) compared safety attitudes in aviation and hospitals, finding differences in team perception. The majority of (resident) surgeons had high scores on cooperation; anaesthesiologists' and (surgical) nurses' views were much lower. Surgical consultants agreed more often than pilots to statements such as "Even when fatigued, I perform effectively during critical times" (60\% vs. $26 \%$ ) and "My decision-making ability is as good in medical emergencies as in routine situations (76\% vs. 64\%). And Bracco et al. (2009) have clearly shown the risks of fatigue due to shift work on reaction time and tracking deviation and its consequences for incidents and errors in anaesthesiology. According to the authors, anaesthesia and aviation share the common theme 'hours of boredom, minutes of thrill, and seconds of terror'. Despite medical specialists' disavowal, stressors as fatigue can have a negative effect on surgical and medical performance. Physician participation in programs like TRM is important but was a challenge for hospital management and the industrial experts. The aviation experts observed that health care professionals had a different view of teamwork and much more autonomy than peers in others industries. Because hospital management could not formally demand medical specialists to participate, incentives were introduced. The flight simulator was also used to 'seduce' physicians into the TRM program. Hospital management and industrial experts did not succeed in introducing live recording of OR procedures because physicians feared legal implications. And, despite hospital policy that a time-out procedure be performed for every surgery, the analysis in the TRM sessions revealed that the procedure had not been carried out. As indicated by Van Stralen (2008), hospitals should also develop into high-reliability organizations with a strong focus on methods to support front-line caregivers and focus on self-efficacy (the belief that one can influence the outcome) and resilience (the use of resources on hand for problem-solving).

The involvement of professionals from another industry proved very helpful in gaining the support of medical professionals and recruiting physician champions. Many physicians and other hospital staff seemed to find aviation an acceptable model for comparison because they could identify with the highly educated pilots. Aviation experts were viewed as credible given the two industries' risk similarities and the fact that aviation experts did not occupy positions in the medical hierarchy. The application of industrial methods can stimulate double-loop learning. The results of the TRM program showed that ophthalmologists and other hospital staff had become increasingly aware of safety issues. The multidisciplinary approach promoted social (team) orientation and thus learning. Professionals are disposed to focus on their own world. Mirroring with other industries stimulates critical views on one's own work and simultaneously catalyzes the diffusion of innovations.

Less recognized but progressively more apparent and demonstrated by these findings is that safety and quality improvements are not single treatment interventions but complex socio-technical interventions. During the program, many TRM aspects were related to organizational aspects outside the scope of the team, like the autonomous position of self-employed medical specialists. As stated, not all ophthalmologists participated in the program; hospital management had neither the position nor power to force them.

Catchpole et al. (2010) measured the effect of aviation-style team training on three surgical teams from different specialties. They concluded that aviation-style teamwork training can increase compliance and team performance but that "the effect was reduced by significant latent failures in organizational and personal management factors such as the attitude and collaboration of key individuals". The training is not always translated into sustained improvement in day-to-day care delivery. This failure to translate awareness into behaviour modification has been object of many studies. For instance, on hand hygiene we know that healthcareassociated infections are considered to be the most frequent as well as the most preventable adverse events, however, the application of hand hygiene measures by health care workers has been deemed to be a complex phenomenon that is not easily explained or changed despite its simplicity (Haynes et al., 2009; Erasmus et al., 2011).

Since safety and quality are relative concepts and has many stakeholders, trade-offs are made between related norms and values, and results vary with the individual and the context (Leistikov 2010). In a study on wrong-site surgery and surgical marking practices, Giles et al. (2006) found differences related to the sociology of medical profession and speciality, practical reasons for variations in marking practice, organizational variations, and variations arising from individual experience. Assessing the 
organizational and social contexts in which interventions are successful, rather than trying to apply strict and artificial controls, is thus important to providing widely generalizable safety and quality improvement.

\section{Conclusion}

Aviation-based team resource management training (TRM) can be a useful approach to stimulating safety culture in hospitals. The TRM program consisted of safety audits, interactive classroom and flight simulator sessions, and video recording of team activities with subsequent feedback. Aviation experts were considered inspiring role models for medical professionals. They had an external perspective without hierarchical barriers or focus on medical-technical issues. Ophthalmologists and other hospital staff became progressively aware of safety issues. The multidisciplinary approach promoted social (team) orientation and diminished the former more functionally-oriented culture. The number of reported near-incidents strongly increased; the number of wrongside surgeries stabilized to a minimum after a substantial reduction in the first years after the program. A multidisciplinary system approach and focus on 'team' instead of 'profession' seems both necessary and difficult in hospital care.

\section{References}

Amalberti, R., Auroy, Y., Berwick, D. et al. (2005), "Five system barriers to achieving ultrasafe health care", Annals of Interne Medicine, Vol. 142, No. 9, pp. 756-764.

Argyris, C. (1991), "Teaching smart people how to learn", Harvard Business Review Vol. 4 No.2, pp.4-15.

Argyris, C. (2004), Reasons and rationalizations: the limits to organizational knowledge. Oxford: Oxford University Press.

Baker, D.P., Day, R., Salas, E. (2006), "Teamwork as an essential component of high-reliability organisations", Health Services Research Vol. 41 No. 4 pp.1576-98.

Balas, E.A., Austin, S.M., Ewigman, B.G., et al. (1995), "Methods of randomized controlled trails in health services research", Medical Care, Vol. 33, pp. 697-699.

Berwick, D.M. (1989), "Continuous improvement as an ideal in health care”, New England Journal of Medicine Vol. 320 Nr. 1, pp.5356 .

Bleakley, A., Hobbs, A., Boyden, J., Walsh, L. (2004), "Safety in operating theatres: improving teamwork through team resource management”, Journal of Workplace Learning Vol. 16, Nr.1/2, pp. 83-91.

Bleakley, A., Allard, J., Hobbs, A. (2012), "Towards culture change in the operating theatre: embedding a complex educational intervention to improve teamwork climate" Medical Teacher Vol 34, pp.e635-40.

Bogner, M. (1994), Human error in medicine. Hillsdale, NJ: Lawrence Erlbaum Associates.

Bowling, A. (2002), Research methods in health. Investigating health and health services. Berkshire: Open University Press.

Bracco, D., Videlier, E., Ramadori, F. (2009), "Anesthesia Crisis Resource Management: Fatigue and Performance", Anesthesiology Rounds Vol. 9 Nr. 1, pp.1-8.

de Bruijne, M.C., Zegers, M., Hoonhout, L.F., et al. (2007), Onbedoelde schade in Nederlandse ziekenhuizen. Dossieronderzoek van ziekenhuisopnames in 2004. [in Dutch]. Amsterdam/Utrecht: EMGO Institute \& NIVEL.

Buljac, M., Dekker, C.M., van Wijngaarden, J.D., et al. (2010), "Interventions to improve team effectiveness: a systematic review", Health Policy, Vol. 94 No. 3, pp. 83-195.

Catchpole, K.R., Dale, T.J., Hirst, D.G., et al. (2010), "A multicenter trial of aviation-style training for surgical teams”, Journal of Patient Safety, Vol. 6 No. 3, pp. 180-186.

Christensen, C.M., Grossman, J.H., Hwang, J. (2009). The Innovators Prescription: a disruptive solution for healthcare. New York: McGrawHill. 
Classen, D.C., Jaser, L., Budnitz, D.S. (2010), “Adverse Drug Events Among Hospitalized Medicare Patients: Epidemiology and National Estimates from a New Approach to Surveillance. Jt Comm J Qual Patient Saf, Vol. 36, pp. 12-21.

Creswell, J.W. (2003). Research design. Qualitative, quantitative and mixed methods approaches. London: Sage Publications.

Denham, C.R. (2005). "Patient safety practices: leaders can turn barriers into accelerators", Patient Safety Vol 1, No. 1, pp. 41-55.

Dunn E.J., Mills, P.D., Neily, J. et al. (2007), "Medical Team Training: Applying crew resource management in the Veterans Health Administration", Jt Comm J Qual Patient Saf, Vol. 33, pp. 317-25.

van Dyck, C. (2000). Putting errors to good use: Error management culture in organizations. Amsterdam: University of Amsterdam.

Van Dyck, C., Dimitrova, N.G., de Korne, D.F., Hiddema, U.F. (2013). "Walk the talk: leaders' enacted priority of safety, incident reporting, and error management", Advances in Health Care Management, Vol.14, pp. 95-117.

Eden, C., Huxham, C. 1996. Action research for management research. British Journal of Management Vol 7, pp. 75-86.

Edmondson, A.C. (2003), "Speaking up in the operating room: how team leaders promote learning in interdisciplinary action teams". Journal of Management Studies, Vol. 40 No. 6, pp. 1419-1452.

Erasmus, V., Huis, A., Oenema, A., et al. (2011), "The ACCOMPLISH study: A cluster randomized trial on the cost-effectiveness of a multicomponent intervention to improve hand hygiene compliance and reduce healthcare associated infections. BMC Public Health, doi:10.1186/1471-2458-11-721.

Flanagan, J. C. (1954). “The critical incident technique”, Psychological Bulletin, Vol. 51, pp. 327-58.

Fraher, A. L. (2005), “Group dynamics for high-risk teams: A 'Team Resource Management' primer”. New York: iUniverse Publications.

Fraher, A. L. (2005), "Team Resource Management (TRM): A Tavistock Approach to Leadership in High-Risk Environments, Resonances of 9/11." Organizational and Social Dynamics, Vol. 5 No. 2, pp. 163-182.

France, D.J., Leming-Lee, S., Jackson, T., Feistritzer, N.R., Higgins, M.S. (2008) "An observational analysis of surgical team compliance with perioperative safety practices after crew resource management training", American Journal of Surgery Vol. 195, pp. 546-553.

Flin, R., Yule, S., McKenzie, L., et al. (2006), "Attitudes to teamwork and safety in the operating theatre", Surgeon, Vol. 4 No. 3 , pp.145-151.

Flin, R., O'Connor, P., Chrichton, M., eds. (2008), Safety at the sharp end: a guide to non-technical skills. Aldershot, UK: Ashgate Publishing.

Freidson, E. (2001), Professionalism. Chicago: University of Chicago Press.

Fulop, F. (2012). "Leadership, clinician managers and the thing called 'hybridity", Journal of Health Organization and Management, Vol. 25, No. 5, pp. 578-604.

Giles, S.J., Rhodes, P., Clements, G., et al. (2006), "Experience of wrong side surgery and surgical marking practices among clinicians in the UK", Quality Safety in Health Care, Vol. 15, pp. 363-368.

Griffin, M.A., Neal, A. (2000), "Perceptions of safety at work: A framework for linking safety climate to safety performance, knowledge and motivation", Journal of Occupational Health Psychology, Vol. 5:347-58.

Gore, D.C., Powell, J.M., Bear, J.G. et al. (2010), "Crew resource management improved perception of patient safety in the operating room." Am J Med Qual, Vol. 25 No. 1, pp. 60-63.

Greenhalgh, T. Robert, G., Bate, P., Macfarlane, F., Kyriakidou, O. (2005), Diffusion of innovations in health services organisations. A systematic literature review. Oxford: Blackwell Publishing.

Grogan, E.L., Stiles, R.A., France, D.J. et al. (2004), "The impact of aviation-based teamwork training on the attitudes of healthcare professionals", J Am Coll Surg, Vol. 199 No. 6, pp. 843-848.

Haig, K.M., Sutton, S., Whittington, J. (2006). "SBAR: a shared mental model for improving communication between clinicians." Joint Commission Journal on Quality and Patient Safety, Vol. 32, No. 3, pp. 167-175. 
Haynes, A.B., Weiser, T.G., Berry, W.R., et al. (2009), "A surgical safety checklist to reduce morbidity and mortality in a global population”, New England Journal of Medicine, Vol. 360, pp. 491-99.

Hudson, P. (2003), "Applying the lessons of high risk industries to health care”, Quality Safety in Health Care, Vol. 12 (Supp.1), pp. i7-i12.

Hoonhout, L.H., de Bruijne, M.C., Wagner, C. et al. (2009), "Direct medical costs of adverse events in Dutch hospitals", BMC Health Services Research, Vol. 9, pp.27.

Hoffman, D.A., Mark, B. (2006). "An investigation of the relationship between safety climate and medication errors as well as other nurse and patient outcomes”, Personnel Psychology, Vol. 59, pp. 847-869.

Institute of Medicine (IOM) (1999), To Err Is Human: Building A Safer Health System. National Academy Press: Washington DC.

Klazinga, N.S. (1996). Quality management of medical specialist care in the Netherlands. An explorative study of its nature and development. Overveen: Belvedere.

IOM (Institute of Medicine) (2012), Best Care at Lower Costs: the path to continuously learning health care in America. National Academy Press: Washington DC.

de Korne, D.F., van Wijngaarden J.D.H., Hiddema, U.F., et al. (2010), "Diffusing aviation innovations in a hospital in the Netherlands", Jt Comm J Qual Patient Saf, Vol. 36 No. 8, pp. 339-347.

Landrigan, C.P., Parry, G.J., Bones, C.B., Hackbarth, et al. (2010), "Temporal trends in rates of patient harm resulting from medical care", New England Journal of Medicine Vol. 363, No. 22, pp. 2124-34.

Langelaan M., Baines, R.J., Broekens, M.A. et al. (2010). Monitor Zorggerelateerde Schade 2008 [in Dutch]. Utrecht: Nivel. Leape, L., Berwick, D., Clancy, D. et al. (2009), "Transforming healthcare: A safety imperative”, Qual Saf Health Care, Vol. 18, pp.424-428.

Leistikov, I.P. (2010), Patient safety: the role of governance [in Dutch], Amsterdam: Elsevier.

Levinson, D.R. (2010), Hospital incident reporting systems do not capture the most patient harm. Washington DC: US Department of Health and Human Services, Office of Inspector General.

van Lieburg, M.J., Rigter, R.B. (1993), Vier eeuwen oogheelkunde in Rotterdam [in Dutch]. Rotterdam: Erasmus Publishing.

McConaughey, E. (2008), "Crew Resource Management in Healthcare: the Evolution of Teamwork Training and MedTeams", Journal of Perinatal and Neonatal Nursing, Vol. 22, No.2, pp. 96-104.

McCulloch, P., Mishra, A., Handa, A., et al. (2009), "The effects of aviation-style non-technical skills training on technical performance and outcome in the operating theatre”, Qual Saf Health Care, Vol. 18 No.2, pp. 109-115.

Mintzberg, H. (1983), Structure in fives: designing effective organizations. Englewood Cliffs: Prentice Hall.

Ministry of Infrastructure \& Environment. (2012), News item. Minor increase of traffic deaths [in Dutch]. http://www.rijksoverheid.nl/nieuws/2012/04/19/lichte-stijging-verkeersdoden-in-2011.html) [last accessed January 8, 2013].

Molloy, G.J., O'Boyle, C.A. (2005), "The SHEL model: a useful tool for analyzing and teaching the contribution of human factors to medical error", Academic Medicine, Vol. 80, pp.152-55.

Musson, D.M., Helmreich, R.L. (2004), "Team training and resource management in health care: current issues and future directions." Harvard Health Policy Review, Vol. 5, pp. 25-35.

Nance, J. (2008), Why hospitals should fly: the ultimate flight plan to patient safety and quality care. Bozeman M.T.: Second River Health Care Press.

Neily, J., Mills, P.D., Young-Xu, Y., et al. (2010), "Association between implementation of a medical team training program and surgical mortality", JAMA, Vol. 304 No. 15, pp. 1693-1700.

Nieva, V.F, Sorra, J.S. (2003), "Safety culture assessments: a tool for improving patient safety in healthcare organizations.", Quality and Safety in Health Care Vol 12, Suppl 2, pp.ii17-ii23.

Oriol, M.D. (2006), "Crew Resource Management: applications in health care organizations", Journal of Nursing Administration, Vol. 36, No. 9, pp. 402-406. 
Pizzi, L., Goldfarb, N.I., Nash, D.B. (2001), "Crew Resource Management and its applications in medicine”. In: Sjohina KG, et al. Making health care safer: a critical analysis of patient safety practices, AHRQ publication 01-E058. San Francisco: Stanford University.

Powell, S.M. (2006), "My co-pilot is a nurse: Using crew resource management in the OR", AORN Journal, Vol. 83, pp. 179-180.

Pronovost, P.J., Goeschel, C.A., Olsen, K.L. et al. (2009), "Reducing health care hazards: lessons from the commercial aviation safety team. Health Affairs 28(3):w479-489.

Rabøl, L.I., Østergard, D., Mogensen, T. (2010), "Outcomes of classroom-based team training interventions for multiprofessional hospital staff. A systematic review." Qual Saf Health Care, Vol. 19:e27.

Reason, J. (1990), Human Error. Cambridge: University Press.

REH. (2010), "Safety culture assessment, a comparison between 2007 and 2009”. [In Dutch; unpublished]. Rotterdam: Rotterdam Eye Hospital.

Rogers, E.M. (1995), Diffusion of innovations, New York City: Free Press.

Sax, H.C., Browne, P., Mayewski, R.J., et al. (2009), "Can aviation-based team training elicit sustainable behavioral change?" Archives of Surgery, Vol. 144, pp. 1133-1137.

Sexton, J.B., Thomas, E.J., Helmreich, R.L. (2000), "Error, stress and teamwork in medicine and aviation: cross sectional surveys." British Medical Journal, Vol. 320, pp. 745-749.

Sexton, J.B., Makary, M.A., Tersigni, A.R. et al. (2006), "Teamwork in the operating room: frontline perspectives among hospitals and operating room personnel”, Anesthesiology, Vol. 105 No. 5, pp. 877-884.

Singer, S.J., Rosen, A., Zhao, S., et al. (2010), "Comparing safety climate in naval aviation and hospitals: implications for improving patient safety", Health Care Management Review, Vol. 35, pp. 134-146.

Singh, H., Petersen, L.A., Thomas, E.J., (2006), “Understanding diagnostic errors in medicine: a lesson from aviation”, Quality Safety in Health Care, Vol. 15, pp. 159-164.

Stralen, D.van. (2008), "High-reliability organizations: Changing the culture of care in two medical units", Design Issues Vol. 24, No. 1, pp. 78-90.

World Health Organization (WHO) (2013),

Yin, R.K. (2003), Case study research: design and methods. London: Sage Publications.

Yule, S., Flin, R., Paterson-Brown, S. et al. (2006), "Non-technical skills for surgeons in the operating room: a review of the literature", Surgery, Vol. 139 No. 2, pp. 140-149. 


\section{Figure 1 Examples of cases used in the TRM program}

\section{Case 1 Unjustified referral to sexually-transmitted diseases center}

In September 2007, a 22-year-old female visited the ophthalmic ER with complaints of an inflamed and irritated eye. The examining resident said things about conjunctivitis and Chlamydia. Microbes were send to the external lab. Upon the next visit, the results were not back, and so they were retrieved by telephone. The resident gave the patient the results and sent her, as protocol required, to the sexually transmitted diseases center for follow-up. (Such patients almost always also have genital Chlamydia.) Upon the third patient visit, the formal results were in the medical record: Chlamydia-negative. What went wrong? Did the resident write a false-positive result down? Was there verification by the microbiologist before the results were sent out? Were the wrong results read over the telephone? Were the wrong results heard? Were the wrong results noted? As a result of analyzing the process, positive results are now not given to the patient without written approval from the microbiologist. The medication is no different and a delay of two days has no relevant influence.

Case 2 Wrong intraocular lens (IOL) power because of similar patient names

In November 2008, two cataract patients with similar-sounding names were prepared for surgery at the ambulatory surgical center. Patient $X$ was scheduled for surgeon $A$; patient $Y$ was scheduled for surgeon $B$. By mistake, patient $X$ was transferred to the $O R$ of surgeon $B$, with the medical record of patient $Y$. Surgeon B implanted an IOL with the power of 18.5 diopter, as noted in the medical record while the patient needed a lens of 10.0 diopter. In meantime, a pre-op nurse noticed the error when performing an anesthetic time-out for patient $Y$. Operating surgeon $B$ first resisted discussing the event, but was pressed by the chief executive of the hospital to cooperate. Analysis showed that the time-out procedure just before incision for patient $X$ was not performed. There was no agreement in the operating team about definition and correct compliance of the time-out procedure. According to some, because a time-out is performed pre-op at the ambulatory surgical center it does not have to be repeated in the OR. Others talked about a 'silent time-out', a control moment without speaking. Also, two new team members had not received the TRM training and that morning the nurses had words about the distribution of tasks. As follow up, a transcript with detailed steps on 'How to perform a time-out' was constructed.

\section{Case 3 Wrong-side eye surgery for strabismus patient}

In August 2009, a 19-year-old female received surgery in the wrong eye. Neither the surgeon nor the pre-and post-operative nurses remarked on the event until the patient's mother called the hospital that night. According to her, her daughter had pain in the unoperated eye. The surgeon was informed the next morning and realized that the surgery was done on the wrong eye. Analysis showed that the chain of events causing the event included: a change of CRNAs between intubations and surgery, unclear requirements for assisting residents, questions about the supervision of a new surgical nurse, and the lack of pre-op briefing. Because the event was revealed almost 24 hours later, it was difficult to reconstruct all the details. The situation stimulated using a video to capture team activities.

\section{Case 4 No patient chart for the macula degeneration patient}

Patient Jansen was scheduled for an Avastin-injection at the macular degeneration department by an ophthalmologist-resident. Due to administrative delays, no paper medical record was available. An OCT was performed based upon the partly filled electronic medical record, from which the most relevant details can be retrieved, e.g., which eye should be treated. To obtain permission from the ophthalmologist, the nurse wrote 'patient Jansen, born 11/08/1938' on a pad and went to the ophthalmologist to ask for signed permission to proceed. The ophthalmologist, however, was busy with another patient and refused to do so. He shouted, in front of patients: 'You crazy nurse, please organize your chart management instead of bothering me with your problems.' The nurse left and went ahead with the patient without formal permission from the ophthalmologist. 
Table 1 TRM participation rates per staff type

\begin{tabular}{lccc}
\hline & $\begin{array}{c}\mathrm{n} \\
\text { (total) }\end{array}$ & $\begin{array}{c}\mathrm{N} \\
(\mathrm{TRM})\end{array}$ & $\begin{array}{c}\text { TRM } \\
\text { participation } \\
\text { rate }\end{array}$ \\
\hline ophthalmologists & 28 & 21 & $75 \%$ \\
anaesthesiologists & 4 & 2 & $50 \%$ \\
internists & 4 & 2 & $50 \%$ \\
residents & 21 & 20 & $95 \%$ \\
surgical nursing & 36 & 34 & $94 \%$ \\
anaesthetic assistants & 18 & 17 & $94 \%$ \\
nursing & 37 & 35 & $95 \%$ \\
outpatient allied health staff & 68 & 65 & $96 \%$ \\
administrative staff & 58 & 56 & $97 \%$ \\
& 274 & 252 & $92 \%$ \\
\hline
\end{tabular}


Table 2 Examples of found risks during safety surgical audit by aviation experts using the SHEL model

L-H negative

1. Emergency button of microscope is too easily touched

2. Unfixed microscope wire on the ground is regularly touched by wheel of surgical chair.

3. Suture wires with unclear thickness

4. Unclear or illegible handwriting

5. No place to put medical record close to surgeon

6. Unclear transport policy of medical gasses during surgery

7. Room temperature too high or too low

8. Sound of radio interferes with sound of phacoemulsification.

9. Culture differences between professional groups

10. Work pressure due to planning of patients

11. Scarce ICT available
L-H positive

1. Good validity of medical equipment

2. Sufficient light

3. Modern anaesthesia equipment

4. Enough workspace

5. Sufficiently trained employees

6. Little hierarchical difference between professions

7. Much attention to patient safety in the hospital
L-S negative

1. No nursing protocol for new treatments

2. Complex control of anaesthesia equipment

3. No standard field for drop anaesthesia in medical record.

4. Time out is not performed in a standard way.

5. Presence of observers give change in procedures

6. No hand-off between ophthalmologist and nurses

7. High authority gradient between anaesthesiologist and CRNA
L-S positive

1. Many protocols provided

2. Time-out protocol is available and used

3. Proper hand-off between CRNAs

4. Mutual team check cornea size

5. Intentions of surgeon are passed to CRNA

6. Proper authority gradient between surgeon and team

SHEL: Software, Hardware, Environment, Liveware;

L-H: lifeware - hardware connection;

L-S: lifeware - software connection 


\section{Table 3 Content of classroom sessions in the TRM program}

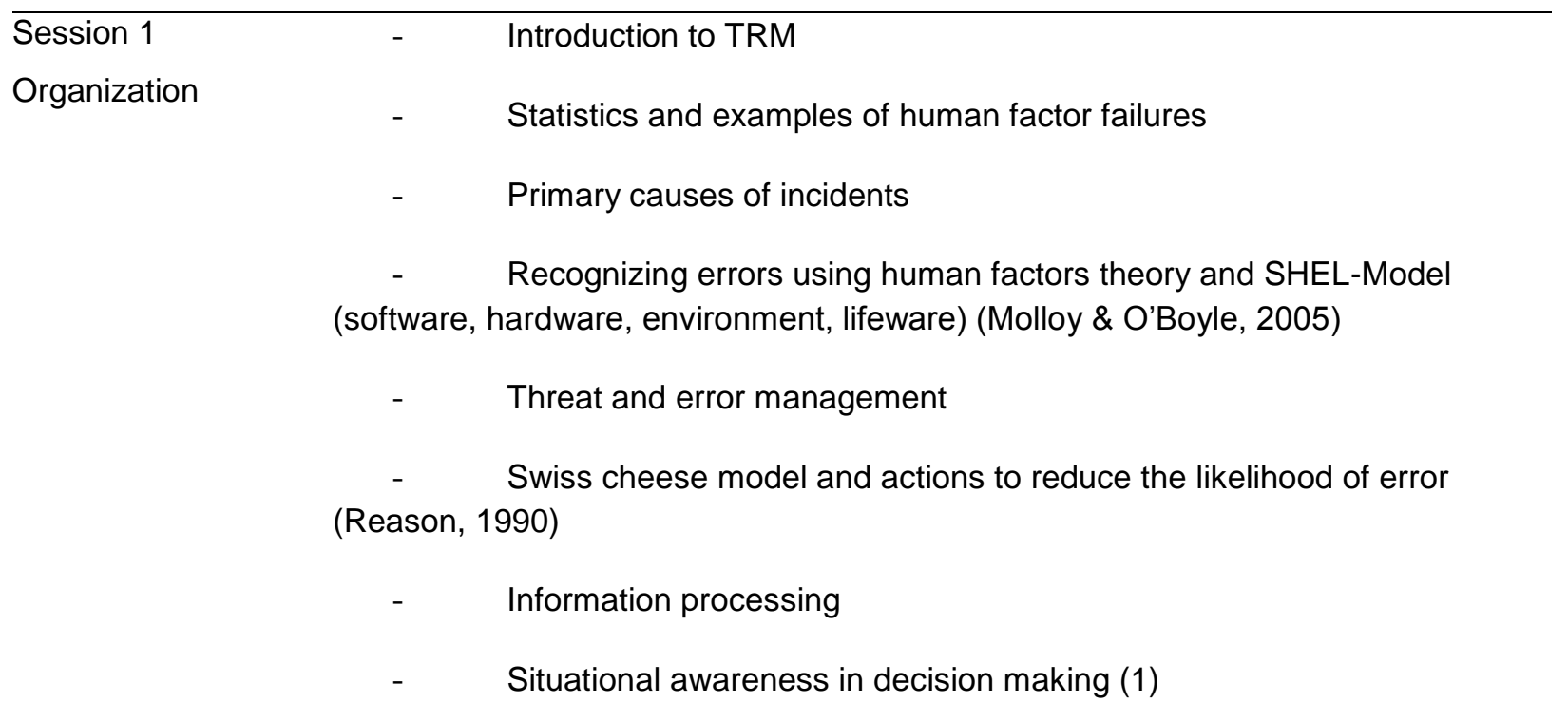

Session 2

- $\quad$ Situational awareness in decision making (2)

Team

- Effective communication and coordination

- $\quad$ TRM loop: Inquiry $\rightarrow$ advocacy $\rightarrow$ conflict resolution $\rightarrow$ decision making

- $\quad$ Leadership and teamwork

- $\quad$ Situational leadership

- Relation- and task-focused

- $\quad$ Feedback: push and pull styles

- $\quad$ Push and pull styles of communication for leaders

- $\quad$ Team exercises

- Personality and behaviour (1)

Session 3

Individual
- Personality and behaviour (2)

- Hazardous attitudes

- How to beat hazardous attitudes

- Personality

- Feedback: theory and exercises 
Table 4 Examples of video observations and feedback to surgical team

\begin{tabular}{lll}
\hline Item & Observation & Feedback \\
\hline Mental preparation & $\begin{array}{l}\text { Before the patient was on the operating table, } \\
\text { who (attending or resident) was supposed to } \\
\text { perform the surgery had not been agreed on. }\end{array}$ & $\begin{array}{l}\text { The performing surgeon is not able to prepare } \\
\text { mentally and obtain situational awareness. }\end{array}$ \\
Briefing & $\begin{array}{l}\text { After the patient arrived in the operating room, } \\
\text { a resident and student received a medical- } \\
\text { technical explanation about the procedure. } \\
\text { There was no talk about who would be } \\
\text { performing what actions or potential problems. } \\
\text { As it turned out, the resident was prepared to } \\
\text { do so. }\end{array}$ & $\begin{array}{l}\text { awareness regarding the competencies of the } \\
\text { colleague performing the operation. To } \\
\text { prevent such errors, he or she briefs him } \\
\text { before on what to expect, so the situational } \\
\text { awareness of the "co-pilot" is updated. The co- } \\
\text { pilot can ask questions or be asked to jump in } \\
\text { during the surgery. This was not made clear to } \\
\text { the team. }\end{array}$ \\
&
\end{tabular}

Projection

Time-Out

New instrument

Communication

Communication

Assertiveness
The ophthalmologist discussed the surgical schedule for the day and indicated that the first surgery in the afternoon was expected to last 2.5 hours. He asked the team to plan their lunch time accordingly.

The time-out was performed, but there was no check against the information in the medical chart.

Halfway during surgery, a scalpel with new tip was on the surgical table. The surgeons did not know why.

The surgeon asks for an intraocular lens (IOL) and the circulating nurse gets one. Before putting it on the table, she says " 20 " but did not receive a response from the surgeon. After a while, the surgeon asks to see the chart to check the IOL power.

Frequently, a task or some material is required, but is not repeated in a standardized manner to confirm that it is understood.

As the ophthalmologist prepared to wash the eye, the circulating nurse asked if the right method and material were used.
This is a good example of correct projection of tasks and managing of resources.

How can we ensure that the time-out procedure is performed in a standard manner?

The fact that surgeons did not know about the new tip can be observed as a "threat" from the organization. Are the communication procedures from the organization to surgeons sufficient, and did the team take responsibility and sufficient measures to prevent errors from such threats?

When the IOL is unpacked, it was shown to be the wrong one. Why not close the communication loop before unpacking the IOL or implement a check moment before?

Communication at surgery is limited (e.g., covered face, working hands, not looking at each other), which every team member should be aware of and try to compensate for. Closing the communication loop during handovers (repeating an assignment, saying "check" or "yes") seems useful.

The circulating nurse's assertiveness was perfect, as was the reaction of the ophthalmologist. 
Table 5 Observations on safety issues before and after the TRM program in the case hospital

\begin{tabular}{|c|c|}
\hline Before & After \\
\hline Paper-based incident report system & Online (near)incident reporting system \\
\hline Central hospital incident committee & $\begin{array}{l}\text { Three decentralized safety committees for surgical, } \\
\text { outpatient and facility (near) incidents. Based on risk } \\
\text { estimation, reports are send to central committee }\end{array}$ \\
\hline Incident investigation done by managers & $\begin{array}{l}\text { Incident investigation done by safety officers and (when } \\
\text { necessary) the independent chair. }\end{array}$ \\
\hline Internal quality audits & Internal quality \& safety audits \\
\hline Protocols focused on department level & $\begin{array}{l}\text { Protocols developing to process focused standard } \\
\text { operation procedures }\end{array}$ \\
\hline No safety rounds & $\begin{array}{l}\text { Safety rounds by CEO, Chief of Surgery, Pharmacist, } \\
\text { Nurse, Technical Officer, Safety Officer }\end{array}$ \\
\hline Safety was on the agenda when incidents occurred & $\begin{array}{l}\text { Every meeting starts with, 'Are there any concerns about } \\
\text { safety?' }\end{array}$ \\
\hline Time-out before surgery & $\begin{array}{l}\text { Time-out including briefing before and debriefing after } \\
\text { surgery }\end{array}$ \\
\hline No formal risk evaluation during performances & $\begin{array}{l}\text { 'Safety eye' used by teams to determine risks and } \\
\text { stimulate professionals to speak up. }\end{array}$ \\
\hline Monodisciplinary protocols on medical gasses & $\begin{array}{l}\text { Multidisciplinary standard operating procedure on logistics } \\
\text { of medical gasses and liquids }\end{array}$ \\
\hline General protocol for intraocular lenses logistics & Specific protocol for extraordinary intraocular lenses \\
\hline No safety instructions for patients & $\begin{array}{l}\text { Safety instructions for patients on website and in paper } \\
\text { flyers }\end{array}$ \\
\hline
\end{tabular}

